\title{
Biology of Big Eyed Bug, Geocoris erythrocephalus (Lepeletier \& Serville) on Cabbage Aphid, Brevicoryne brassicae (L.)
}

\author{
S. Jesu Rajan ${ }^{1}$, E. Sree Latha ${ }^{1}$ and R. Sathish ${ }^{2}$ \\ ${ }^{1}$ Centre for Biocontrol Laboratory, National Institute of Plant Health Management \\ (NIPHM), Hyderabad-500 030, Telangana, India \\ ${ }^{2}$ Agricultural Polytechnic, Prof. Jayashankar TS Agricultural University, Hyderabad, India \\ *Corresponding author
}

\section{Keywords}

Big eyed bug,

Geocoris,

Fecundity, Life cycle, Longevity

Article Info

Accepted:

24 June 2018

Available Online:

10 July 2018
Biology of big eyed bug, Geocoris erythrocephalus (Lepeletier \& Serville) was studied oncabbage aphid, Brevicoryne brassicae (L.) at Centre for biocontrol laboratory, National Institute of Plant Health Management (NIPHM), Hyderabad during 2017.Studies showed the incubation period as $8.20 \pm 0.42$ days. There were total five nymphal instars and average duration of each successive instar was 4.40 $\pm 0.52,8.50 \pm 0.53,6.70 \pm 0.48,7.60 \pm 0.52$ and $5.20 \pm 0.42$ days, respectively. The average fecundity was $14.00 \pm 3.06$ eggs with an oviposition period of $3.80 \pm$ 0.63 days. The adult longevity of male and female bugs was $7.40 \pm 0.52$ days and $11.50 \pm 0.85$ days, respectively. The average total life cycle was completed in $40.60 \pm 2.89$ days.

\section{Introduction}

Geocoris is a genus of insects in the family Geocoridae commonly known as big eyed bugs. Geocoris species are considered to be among the most important predators in cotton, maize, alfalfa, soyabean, straw berry, pea nut and many other crops (Crocker and Whitcomb, 1980). They are commonly known as "big-eyed bugs" due to the characteristic large, prominent, widely separated eyes on both sides of their head. Geocoris species are important predators found in nature and agroecosystems (Sweet, 2000). They actively hunt their victims, and their big eyes give them a wide field of vision and boost their ability to locate prey. Once have found a meal, they insert their stylet ("needle sharp beak"), inject digestive enzymes, and then suck up the partially digested insides of their prey, leaving behind a hollow cadaver. Both the nymphs and adults feed on aphids, whiteflies, thrips, mites, and the eggs and larvae of caterpillars such as tobacco budworm, bollworm and soybean loopers (Bueno and Van Lenteren, 2012). In addition, they are also predators of plant bugs, especially the younger nymphs. According to Anonymous (2017) in one laboratory study, bigeyed bug nymph consumes an average of 151 tobacco budworm 
eggs or 76 first instar larvae during the to complete all five nymphal instars in 21-31 days. Late instar nymphs consumed approximately 10 eggs per day (Anon., 2017). Like many predatory insects in this order, big eyed bugs also feed on nectar and directly on plants, causing little or no damage, but their populations may be affected by systemic insecticides.

Apparently scanty and scattered information is available on the biology of this predator in India. Hence, the present study was carried out under laboratory conditions to determine the life cycle of $G$. erythrocephalus.

\section{Materials and Methods}

Studies on the biology of G. erythrocephalus were conducted in Centre for biocontrol laboratory, National Institute of Plant Health Management (NIPHM), Hyderabad during 2017-18. Stock culture of the $G$. erythrocephalus was initiated by collecting large number of adults (male and female) from the sweet corn field of NIPHM, Hyderabad. The adults acclimatized under laboratory conditions by rearing for two generations on UV-irradiated Corcyra cephalonica Staint on eggs before initiating the experiments.

\section{Biology}

The adult G. erythrocephalus lays eggs singly on cottonwick or cloth (Richa and Ballal, 2017). Hence, from the lab reared $G$. erythrocephalus culture, one pair of adult was released into each glass beaker $(1000 \mathrm{ml})$ covered with muslin cloth. Ten such sets were maintained. Each container was provided with UV-irradiated C.cephalonica eggs and cotton wick for egg laying. After every $24 \mathrm{~h}$, cotton wicks were collected and observed under microscope to record number of eggs laid. Eggs were laid on cloth surface too. The eggs were counted and kept on sterilized blotting paper in small petri dishes to record incubation period. The petri dishes bearing the known numbers of eggs (10 eggs) were kept at laboratory temperature (27 to 30 ) and relative humidity (60 to 70) for studying different parameters. The emerging predatory nymphs were removed instantaneously with fine brush, kept in plastic boxes provided with cabbage aphids (Brevicoryne brassicae) as a food.

Ten freshly hatched nymphs per set were kept individually in plastic boxes provided $B$. brassicae. Observations were recorded on total number of instars, duration of each instar and total nymphal period. When adults were formed, they were collected and observed under microscope to differentiate the sex.The total number of eggs laid (fecundity) by each female during its lifetime, the longevity of male and female adults and their sex ratio were also recorded.

\section{Host rearing}

The cabbage leaves infested with aphids kept in plastic boxes were supplied as food for nymphs of $G$. erythrocephalus continuously starting from nymph to adult. The leaf stalks of aphid infested cabbage leaves endowed with water soaked cotton to prevent the drying of leaves.

\section{Statistical analysis}

Each experiment was replicated five times and the arithmetic mean and standard error of mean were estimated for all the parameters/observations. Range values were also estimated by pooling up the replication data for each parameter.

\section{Results and Discussion}

Females start laying eggs after a duration of 23 (av. $2.30 \pm 0.48$ ) days. The adult female lays eggs on cotton wick provided inside the 
beaker. It indicated that, hairiness is preferable for egg laying by the adult females. A single female lays 10-21 (av.14.00 \pm 3.06 ) eggs in 35 (av.3.80 \pm 0.63$)$ days of ovipositional period (Table 1).

\section{Egg}

The eggs of G. erythrocephalus were spindle shape laid singly on cotton fibrils. Eggs were light yellowish initially with two red spots at the blunt end. These two red eyespots help distinguish them from other insect eggs. As the days progress the eggs turns darker and red colour spots became prominent. These observations are in line with the Richa and Ballal (2017) who noticed similar observation on egg of Geocoris superbus Montandon. The incubation period ranged from 8 to 9 (av. 8.20 \pm 0.42 ) days (Table 1). This result in corroborate with the Mansfield et al., (2017) observed incubation period of 8.35 days in case of Geocoris lubra Kirkaldy.

\section{Nymph}

Geocoris nymphs look similar to adults, only smaller and without wings. Nymphal stages have similar behaviour and feeding habits as adults, but tend to feed on smaller prey. Bugs have undergone five nymphalin stars in 3035 (av.32.40 \pm 2.47 ) days. The duration of I, II, III, IV and V instar nymphs were 4-5 (av. 4.40 \pm 0.52 ), 8-9 (av.8.50 \pm 0.53), 6-7(av. $6.70 \pm$ 0.48 ), 7-8(av. 7.60 \pm 0.52 ) and 5-6 (av. 5.20 \pm 0.42 ) days, respectively (Table 1). The present findings are in line with the findings of Ramirez et al., (2011) who noticed nymphs emerge and develop over 3-4 weeks. Young instars are tiny and are easily overlooked. With each successive instar they shed their skin, develop wing pads, and grow larger.

Table.1 Biology of big eyed bug, G. erythrocephalus under laboratory conditions

\begin{tabular}{|c|l|c|c|}
\hline Sl.No. & \multicolumn{1}{|c|}{ Stage } & Range & $\begin{array}{c}\text { Duration } \\
(\text { SE.m } \pm \text { S.D })\end{array}$ \\
\hline $\mathbf{1 .}$ & Pre- oviposition & $2-3$ & $2.30 \pm 0.48$ \\
\hline $\mathbf{2 .}$ & Oviposition period & $3-5$ & $3.80 \pm 0.63$ \\
\hline $\mathbf{3 .}$ & Post oviposition & $4-6$ & $5.40 \pm 1.17$ \\
\hline $\mathbf{3 .}$ & Fecundity & $10-21$ & $14.00 \pm 3.06$ \\
\hline $\mathbf{4 .}$ & Incubation period & $8-9$ & $8.20 \pm 0.42$ \\
\hline $\mathbf{5 .}$ & Nymphal period & $4-5$ & \\
\hline & I Instar & $8-9$ & $8.40 \pm 0.52$ \\
\hline & II Instar & $6-7$ & $6.70 \pm 0.43$ \\
\hline & III Instar & $7-8$ & $7.60 \pm 0.52$ \\
\hline & IV Instar & $5-6$ & $5.20 \pm 0.42$ \\
\hline & V Instar & $30-35$ & $32.40 \pm 2.47$ \\
\hline & Total nymphalperiod & $38-44$ & $40.60 \pm 2.89$ \\
\hline $\mathbf{6 .}$ & Total life cycle & $1: 0.83-1: 1.72$ & $1: 1.29$ \\
\hline $\mathbf{7 .}$ & Sex ratio & $7-8$ & $7.40 \pm 0.52$ \\
\hline $\mathbf{8 .}$ & Adult & $10-13$ & $11.50 \pm 0.85$ \\
\hline & Male & Female &
\end{tabular}




\section{Adult}

Adults are 3-5 mm (3/16 inch or less) long with 2 pairs of fully functional wings (forewings and hindwings). The forewings are hardened at the base and membranous at the tip. At rest the forewings cross over the back, one over the other, creating a triangle pattern behind the pronotum ("shoulders"), pointing toward the rear. Adult bugs exhibits sexual diamorphism. Females are bigger in size than males. Anterior portion of head (in between eyes) looks golden yellow in females whereas in males it looks brown.

After the adult formation females live longer than males. Longevity of female and males were 10-13 (av. 11.50 \pm 0.85) and 7-8 (av. $7.40 \pm 0.52$ ) days, respectively (Table 1 ). Male and female ratio was observed to be 1:1.29. G. erythrocephalus took 38-44 (av. $40.60 \pm 2.89$ ) days for completion of its life cycle. For other Geocoris species, total developmental period of 40 days and 35 days were recorded in case of Geocoris bullatus (Say) and Geocorispallens Stål, respectively when reared on aphids, beans and sunflower seeds (Tamaki and Weeks, 1972) and 47.50 to 50.50 days in case of G.superbusreared onPhenacoccussolenopsis Tinsley(Richa and Ballal, 2017). Mead (2011) found the averagedevelopment time from egg to adult of bugs was 30 days. This variation in developmental period may be due to change in location.

In conclusion, the present study indicates that, this predator is effective on Cabbage aphid, Brevicoryne brassicae (L.) and further studies need to be done to confirm its feeding potential and to exploit this predator for control of aphids which attackvarious crops.

\section{Acknowledgement}

The authors are thankfully acknowledged to Dr.Chitra Shanker, Senior Scientist, Indian
Institute of Rice Research (IIRR), Hyderabad for taxonomical identification of big eyed bug, Geocoris erythrocephalus (Lepeletier \&Serville). Authors also gratefully thank to the Director General, National Institute of Plant Health Management (NIPHM), Hyderabad, for the facilities provided for conducting the study.

\section{References}

Annonymous, 2017, http://utcrops.com/ cotton/cotton_insects/Biocontrol/BEB.h tm

Bueno, V. H. P. and Van Lenteren, J. C., 2012, Predatory bugs (Heteroptera). In Panizzi A.R. and Parra J.R.P. (eds): Insect Bioecology and Nutrition for Integrated Pest Management. CRC Press, Boca Raton, pp. 51-70.

Crocker, R. L. and Whitcomb, W. H., 1980, Feeding niches of the bigeyed bugs Geocorisbullatus, G. punctipes, and G. uliginosus (Hemiptera: Lygaeidae: Geocorinae). Environmental Entomology, 9:508-513.

Mansfield S., Scholz, B., Armitage, S. and Johnson, M. L., 2007, Effects of diet, temperature and photoperiod on development and survival of the bigeyed bug, Geocoris lubra. Bio Control,52:63-74.

Mead, F. W. (2011), Big-Eyed Bugs, Geocoris spp. (Insecta: Hemiptera: Lygaeidae). Florida Department of Agriculture and Consumer Services, Division of Plant Industry, Gainesville, pp.1-6.

Ramirez, R., Patterson, R. and Carbon, C, 2011, Beneficial True Bugs: Big-Eyed Bugs. Utah State University Extension and Utah Plant Pest Diagnostic Laboratory, ENT-159-11PR.

Richa V. and Ballal, C. R., 2017, Biology and feeding potential of Geocorissuperbus Montandon (Heteroptera: Geocoridae), a predator of mealybug. Journal of 
Entomology and Zoology Studies,5(3): $520-524$.

Sweet, M. H., 2000, Economic importance of predation by bigeyed bugs
(Geocoridae). In Schaefer C.W. and Panizzi A.R.(eds): Heteroptera of Economic Importance. CRC Press, Boca Raton, pp. 713-724.

\section{How to cite this article:}

Jesu Rajan, S., E. Sree Latha and Sathish, R. 2018. Biology of Big Eyed Bug, Geocoris erythrocephalus (Lepeletier \& Serville) on Cabbage Aphid, Brevicoryne brassicae (L.). Int.J.Curr.Microbiol.App.Sci. 7(07): 3301-3305. doi: https://doi.org/10.20546/ijcmas.2018.707.384 